\title{
Transcriptome analysis of two inflorescence branching mutants reveals cytokinin is an important regulator in controlling inflorescence architecture in the woody plant Jatropha curcas
}

Mao-Sheng Chen ${ }^{1,2}$, Mei-Li Zhao ${ }^{1,3}$, Gui-Juan Wang ${ }^{1}$, Hui-Ying He ${ }^{1,2}$, Xue Bai ${ }^{1,3}$, Bang-Zhen Pan ${ }^{1,2}$, Qian-Tang Fu ${ }^{1,2}$, Yan-Bin Tao ${ }^{1,2}$, Ming-Yong Tang ${ }^{1,2}$, Jorge Martínez-Herrera ${ }^{4}$ and Zeng-Fu Xu ${ }^{1,2^{*}}$ (D)

\begin{abstract}
Background: In higher plants, inflorescence architecture is an important agronomic trait directly determining seed yield. However, little information is available on the regulatory mechanism of inflorescence development in perennial woody plants. Based on two inflorescence branching mutants, we investigated the transcriptome differences in inflorescence buds between two mutants and wild-type (WT) plants by RNA-Seq to identify the genes and regulatory networks controlling inflorescence architecture in Jatropha curcas L., a perennial woody plant belonging to Euphorbiaceae.

Results: Two inflorescence branching mutants were identified in germplasm collection of Jatropha. The duo xiao hua $(d x h)$ mutant has a seven-order branch inflorescence, and the gynoecy $(g)$ mutant has a three-order branch inflorescence, while WT Jatropha has predominantly four-order branch inflorescence, occasionally the three- or five-order branch inflorescences in fields. Using weighted gene correlation network analysis (WGCNA), we identified several hub genes involved in the cytokinin metabolic pathway from modules highly associated with inflorescence phenotypes. Among them, Jatropha ADENOSINE KINASE 2 (JCADK2), ADENINE PHOSPHORIBOSYL TRANSFERASE 1 (JCAPT1), CYTOKININ OXIDASE 3 (JCCKX3), ISOPENTENYLTRANSFERASE 5 (JCIPT5), LONELY GUY 3 (JCLOG3) and JCLOG5 may participate in cytokinin metabolic pathway in Jatropha. Consistently, exogenous application of cytokinin (6-benzyladenine, 6-BA) on inflorescence buds induced high-branch inflorescence phenotype in both low-branch inflorescence mutant $(g)$ and WT plants. These results suggested that cytokinin is an important regulator in controlling inflorescence branching in Jatropha. In addition, comparative transcriptome analysis showed that Arabidopsis homologous genes Jatropha AGAMOUS-LIKE 6 (JCAGL6), JCAGL24, FRUITFUL (JCFUL), LEAFY (JCLFY), SEPALLATAS (JCSEPS), TERMINAL FLOWER 1 (JCTFL1), and WUSCHEL-RELATED HOMEOBOX 3 (JCWOX3), were differentially expressed in inflorescence buds between $d \times h$ and $g$ mutants and WT plants, indicating that they may participate in inflorescence development in Jatropha. The expression of JCTFL 1 was downregulated, while the expression of JCLFY and JCAP1 were upregulated in inflorescences in low-branch $g$ mutant.

(Continued on next page)
\end{abstract}

\footnotetext{
* Correspondence: zfxu@xtbg.ac.cn

${ }^{1}$ CAS Key Laboratory of Tropical Plant Resources and Sustainable Use,

Xishuangbanna Tropical Botanical Garden, The Innovative Academy of Seed

Design, Chinese Academy of Sciences, Menglun, Mengla 666303, Yunnan,

China

${ }^{2}$ Center of Economic Botany, Core Botanical Gardens, Chinese Academy of

Sciences, Menglun, Mengla 666303, Yunnan, China

Full list of author information is available at the end of the article
}

(c) The Author(s). 2019 Open Access This article is distributed under the terms of the Creative Commons Attribution 4.0 International License (http://creativecommons.org/licenses/by/4.0/), which permits unrestricted use, distribution, and reproduction in any medium, provided you give appropriate credit to the original author(s) and the source, provide a link to the Creative Commons license, and indicate if changes were made. The Creative Commons Public Domain Dedication waiver (http://creativecommons.org/publicdomain/zero/1.0/) applies to the data made available in this article, unless otherwise stated. 
(Continued from previous page)

Conclusions: Cytokinin is an important regulator in controlling inflorescence branching in Jatropha. The regulation of inflorescence architecture by the genes involved in floral development, including TFL 1, LFY and AP1, may be conservative in Jatropha and Arabidopsis. Our results provide helpful information for elucidating the regulatory mechanism of inflorescence architecture in Jatropha.

Keywords: Branching, Cytokinin, Inflorescence, Physic nut, WGCNA analysis

\section{Background}

Inflorescence architecture directly influencing plant reproductive success [1], is a key agronomic factor determining seed yield. In higher plants, inflorescence architectures exhibit remarkable diversity, which is derived from the inflorescence position on the shoot, the flower arrangement within inflorescence and the patterns and timing of flower initiation during reproductive development $[2,3]$. Recently, a detailed review has been made on evolutionary developmental biology studies of inflorescence architecture [4]. In inflorescence development, the maintenance of the inflorescence meristem and initiation of the floral meristem are critical to determine inflorescence architecture. In Arabidopsis thaliana, CLAVATA (CLV) pathways regulate meristem maintenance by restricting the expression of WUSCHEL (WUS), which defines the stem cell niche $[5,6]$. A mutation in CLAVATA (CLV1, CLV2 or $C L V 3)$ results in the accumulation of meristem cells to generate an increased shoot meristem dome [7]. Mutation in WUS causes defective shoot and floral meristems [6]. In maize, thick tassel dwarf1 (td1) and fasciated ear2 (fea2) are orthologs of $C L V 1$ and $C L V 2$, respectively. Loss-offunction mutant $t d 1$ exhibits a fascinated ear with extra rows of kernels and a tassel with more dense spikelets [8]. The fea 2 mutant exhibits a massive ear inflorescence meristem and increased organ number [9].

In Arabidopsis, the transition time from the inflorescence to floral meristem is critical in the determination of inflorescence architecture; TERMINAL FLOWER1 (TFL1), LEAFY (LFY) and APETALA1 (AP1) participate in this process and regulate inflorescence branching patterns $[10,11]$. TFL mutation promotes the conversion of the inflorescence meristem into the floral meristem, causing an abnormal inflorescence with a compound floral structure [12]. By contrast, the ectopic expression of TFL1 in a transgenic plant induces a highly branched inflorescence phenotype in Arabidopsis [13]. Conversely, $L F Y$ and $A P 1$ repress the expression of TFL1 in the floral meristem [11, 14]. Moreover, SUPPRESSOR OF OVEREXPRESSION OF CONSTANS 1 (SOC1), SHORT VEGETATIVE PHASE (SVP), AGAMOUS-LIKE 24 (AGL24), and SEPALLATA 4 (SEP4) redundantly regulate inflorescence architecture by directly suppressing the expression of TFL1; a soc1-2 agl24-3 svp-41 sep4-1 quadruple mutant displays a massive inflorescence branching phenotype [15].

Overexpression of rice $R C N 1$ and $R C N 2$ and maize ZCN1-ZCN6, which are homologous to Arabidopsis TFL1, causes highly branched inflorescences through maintaining the indeterminacy of the inflorescence meristem $[16,17]$. Rice TAWAWA1 (TAW1) regulates inflorescence architecture by suppressing the specification of the spikelet meristem to maintain the indeterminacy of inflorescence architecture [18]. A gain-of-function mutant, tawawa1-D, exhibits a highly branched inflorescence and increased number of spikelets, whereas a $T A W 1$ knockdown mutant displays a small, reduced branching inflorescence resulting from early termination of inflorescence meristems and the formation of spikelet meristems [18]. In rice, the WEALTHY FARMER'S PANICLE (WFP)/ IDEAL PLANT ARCHITECTURE (IPA1) locus is linked to a Squamosa Promoter Binding Protein-Like 14 (OsSPL14) gene that can be suppressed by OsmiR156 [19]. A single nucleotide change in OsSPL14 that relieves the repression of OsmiR156 causes increased panicle branching and grain number $[19,20]$. Overexpression of a maize $U N$ BRANCHED3 (UB3), an ortholog of rice OsSPL14, dramatically repressed tillering and panicle branching in rice; however, moderate expression of UB3 slightly suppressed tillering, but promoted panicle branching, resulting in an increased grain number per panicle in rice [21, 22].

In maize, two APETALA2-like genes, indeterminate spikelet1 (ids1) and sister of indeterminate spikelet 1 (SID1), are required for inflorescence branching by regulating the initiation of spikelet meristem and floral meristem, and an ids1 sid1 double mutant shows a reduced branching inflorescence phenotype [23]. Three maize genes, RAMOSA1 (RA1), RA2 and $R A 3$, regulate the fate of the inflorescence meristem, and mutations in these genes cause an increased long-branching inflorescence [24-26].

Plant hormones such as auxin and cytokinin are required for the initiation and outgrowth of axillary meristems that generate inflorescence branches and florets during reproductive development [27, 28]. Several auxin biosynthesis and polar transport components, such as YUCCA (YUC), PIN-FORMED 1 (PIN1) and PINOID (PID), are important regulators in inflorescence development [27]. In Arabidopsis, the YUC gene encodes flavin 
monooxygenases (FMOs) that catalyze a rate-limiting step in tryptophan-dependent auxin biosynthesis; overexpression of YUC promotes auxin levels during development processes [29]. In maize, sparse inflorescence1 (spi1), a homologous Arabidopsis YUC, encodes a FMO, and spi1 mutation reveals defects in the initiation of axillary meristems and lateral organs, causing reduced branch number and floral organs in inflorescences [30]. Auxin transport proteins PIN1 and PID are required for the distribution of auxin; mutation in pin1 or pid causes a pin-like inflorescence with abnormal flowers because of defects in the initiation of the axillary meristem in Arabidopsis [31, 32]. Maize barreninflorescence2 (bif2), an ortholog of PID, is required for the initiation of the axillary meristem and lateral primordia; the bif2 mutant displays a reduced number of branches, spikelets, florets and kernels in inflorescences [33]. Barren inflorescence1 (bif1) mutation causes a similar phenotype to that of the bif2 mutant [34]; the barren stalk1 (ba1) mutant displays an unbranched inflorescence without spikelets because of a defect in auxin signaling [35]. In Setaria viridis, SvAUXIN1 is required for inflorescence development and its loss-of-function mutant sparse panicle1 (spp1) displays reduced and uneven inflorescence branching phenotype [36].

Cytokinin is required for meristem activity and plays a positive role in the shoot meristem [37]. In Arabidopsis, CYTOKININ OXIDASE 3 (CKX3) and CKX5 catalyze the degradation of cytokinin; $c k x 3 c k x 5$ double mutant display larger inflorescences and floral meristems because of the accumulation of cytokinin [38]. In rice, a QTL locus, Gn1, encodes an OsCKX2; the reduced expression of OsCKX2 causes higher cytokinin levels in the inflorescence meristem to increase the number of branches and spikelets, leading to enhanced grain yield [39]. A zinc finger transcription factor, DROUGHT AND SALT TOLERANCE (DST), directly regulates the accumulation of cytokinin in the shoot apical meristem (SAM) to promote panicle branching loading to the increase of grain number [40]. The LONELY GUY (LOG) gene encodes an enzyme that participates in the final step of bioactive cytokinin synthesis; mutation in $\log$ causes a small inflorescence with reduced branch and spikelet number [37].

At present, the studies on molecular mechanism of inflorescence architecture are focus on the model plants and few in perennial woody plants because of their long reproductive cycle and the difficulty in the establishment of genetic transformation system. To understand the regulatory mechanism of inflorescence architecture, the investigation of the evolutionary changes in developmental morphology and the identification of key factors controlling inflorescence development are crucial in closely related plant lineages that display different inflorescence structures [4], especially, in perennial woody plants.
Jatropha curcas L. has high seed oil content and is considered a potential biofuel plant [41, 42]. The Jatropha inflorescence exhibits a dichasial cyme pattern bearing male and female flowers in the same inflorescence. Few female flowers per inflorescence is considered one of the factors leading to poor seed yield in Jatropha [43]. Our previous research showed that co-suppression of JCLFY delayed flower formation, leading to production of more secondary inflorescence branches [44], but roles of $J_{c T F L 1 b}[44,45]$ and $J_{c A P 1}[46]$ in inflorescence branching remain unclear. Paclobutrazol (PAC), an inhibitor of gibberellin biosynthesis, causes compacted inflorescences with short branches, resulting in increased seed yield in Jatropha [47, 48]. Cytokinin treatment on inflorescence buds generated a larger inflorescence with a significantly increased the number of female and total flowers [43, 49 , 50], which means a high-branch inflorescence phenotype. These results suggest that cytokinin may play a significant role in the determination of inflorescence architecture in Jatropha. In this study, two Jatropha mutants that exhibit different inflorescence branching traits were used for comparative transcriptome analysis to identify genes and regulation networks that participate in the regulation of inflorescence architecture. Our study will contribute to the understanding of the genetic basis of inflorescence architecture and to the breeding of high-yield Jatropha varieties.

\section{Results}

$d x h$ and $g$ mutants have different inflorescence branching phenotypes

In general, wild-type (WT) Jatropha has a four-order branch cyme inflorescence bearing female and male flowers, and three- or five-order branch inflorescence is occurred occasionally in different growth conditions. Here, we reported two inflorescence branching mutants: a high-branch $d x h$ (Chinese for "more florets") mutant with a seven-order branch inflorescence, which came from a mutagenized population treated with cobalt-60 gamma rays; a low-branch $g$ mutant with a three-order branch inflorescence, which originated from a natural mutation [51] (Fig. 1). In the $d x h$ mutant, the total flower number, female flower number, fruit number, seed number, seed yield and oil content were significantly increased, whereas the female-to-male ratio was decreased, and the 100-seed weight remained constant in $d x h$ mutant plants compared with those in WT plants (Fig. 2). The increase in seed yield and oil content and the constant 100 -seed weight in $d x h$ plants indicated that the $d x h$ mutant is an excellent material for breeding high-yield Jatropha varieties. The $g$ mutant had a gynoecious genotype with normal female flowers, whereas male flowers were aborted, indicating that it is also good breeding material. 


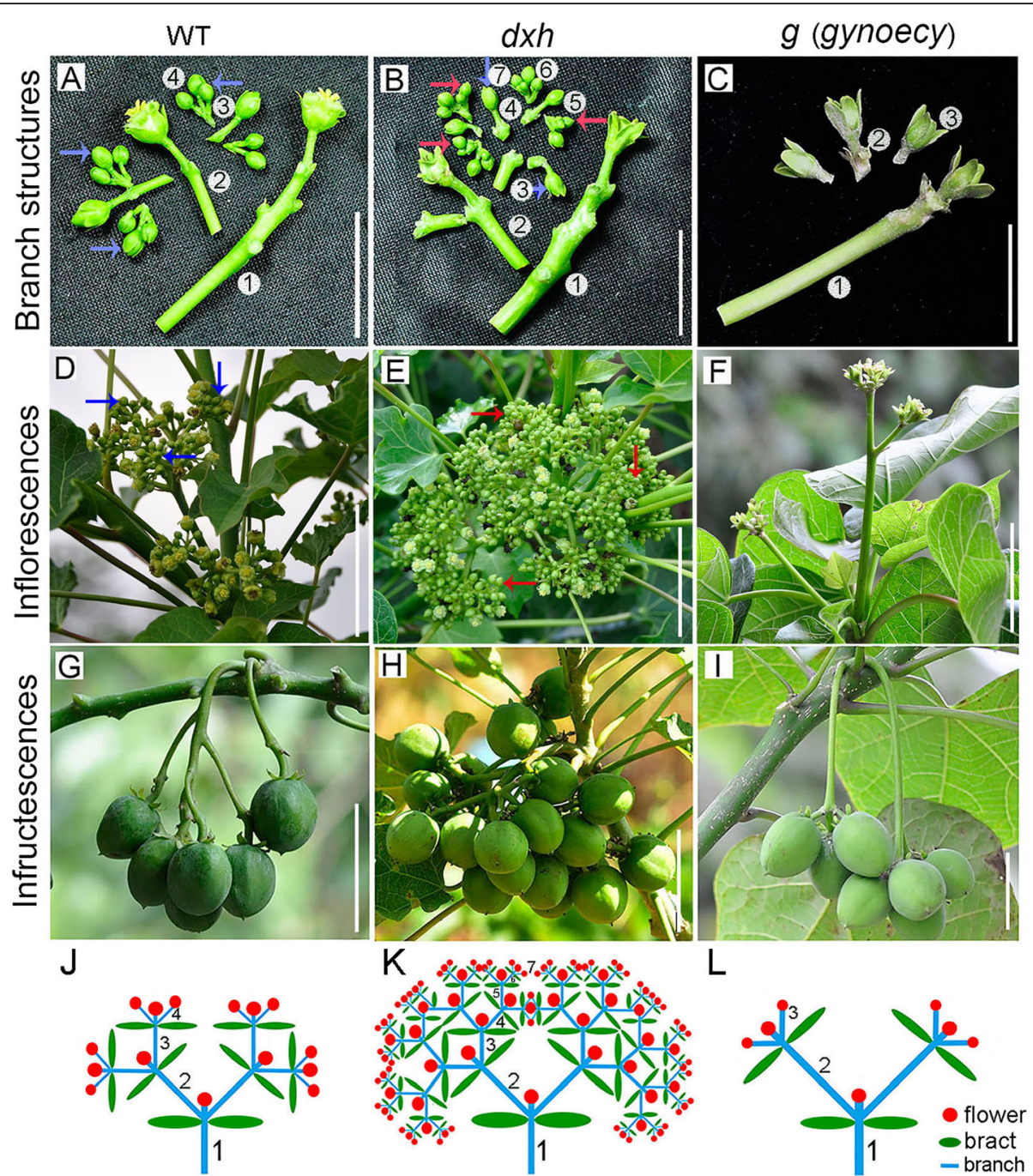

Fig. 1 Phenotypes of inflorescence branching of WT and $d x h$ and $g$ mutants. a-c indicate the branching structure of inflorescences in WT and $d x h$ and $g$ mutants, respectively. Bar $=2.0 \mathrm{~cm}$. $\mathbf{d}$-f f indicate the intact inflorescences of WT and $d x h$ and $g$ mutants. In panels $\mathbf{a}, \mathbf{b}$, $\mathbf{d}$ and $\mathbf{e}$, the blue arrows indicate the fourth branching, and the red arrows denote the seventh branching. $B a r=5.0 \mathrm{~cm}$. $\mathbf{g}$-i indicate the infructescences of WT and $d x h$ and $g$ mutants. Bar $=5.0 \mathrm{~cm}$. $\mathbf{j}-\mathbf{I}$ indicate the diagrammatic sketch of inflorescence structure of WT and $d x h$ and $g$ mutants

\section{Identification of differentially expressed genes}

To investigate the regulatory mechanism underlying inflorescence branching, we carried out RNA-Seq analysis between five group samples to identify DEGs (Additional file 1). These samples contained shoot tips that can generate inflorescence meristem and inflorescence buds from WT plants (hereafter referred to as ckI and ckII), shoot tips and inflorescence buds from the $d x h$ mutant (referred to as dxhI and dxhII), and inflorescence buds from the $g$ mutant (referred to as gII). A multidimensional scaling (MDS) plot showed that ckI, dxhI and gII samples can be well separated from ckII and dxhII based on the biological coefficient of variation (BCV) (Additional file 2). The close relationship between high-branch mutant (dxhII) and WT (ckII) inflorescence samples indicated that they have highly similar gene expression profiles. For simplicity, we hereafter refer to the comparison of ckII vs. ckI as ckII_ckI, dxhII vs. dxhI as dxhII_dxhI, dxhI vs. ckI as dxhI_ckI, dxhII vs. ckII as dxhII_ckII, gII vs. ckII as gII_ckII, and gII vs. dxhII as gII_dxhII. In the six pairs, 3549 DEGs in ckII_ckI, 410 in dxhII_dxhI, 2089 in dxhI_ckI, 329 in dxhII_ckII, 12, 413 in gII_ckII and 12,282 in gII_dxhII were identified at an FDR of $<0.05$ (Additional files 3 and 4). Among them, we identified 28 DEGs that have opposite expression patterns in inflorescences between pairwise high-branch mutant vs. WT (dxhII_ckII) and low-branch mutant vs. WT (gII_ckII) (Fig. 3 and Additional file 5). Expression of two genes of them were upregulated in inflorescences in pairwise high-branch mutant vs. WT (dxhII_ckII) and downregulated in pairwise low-branch mutant vs. 

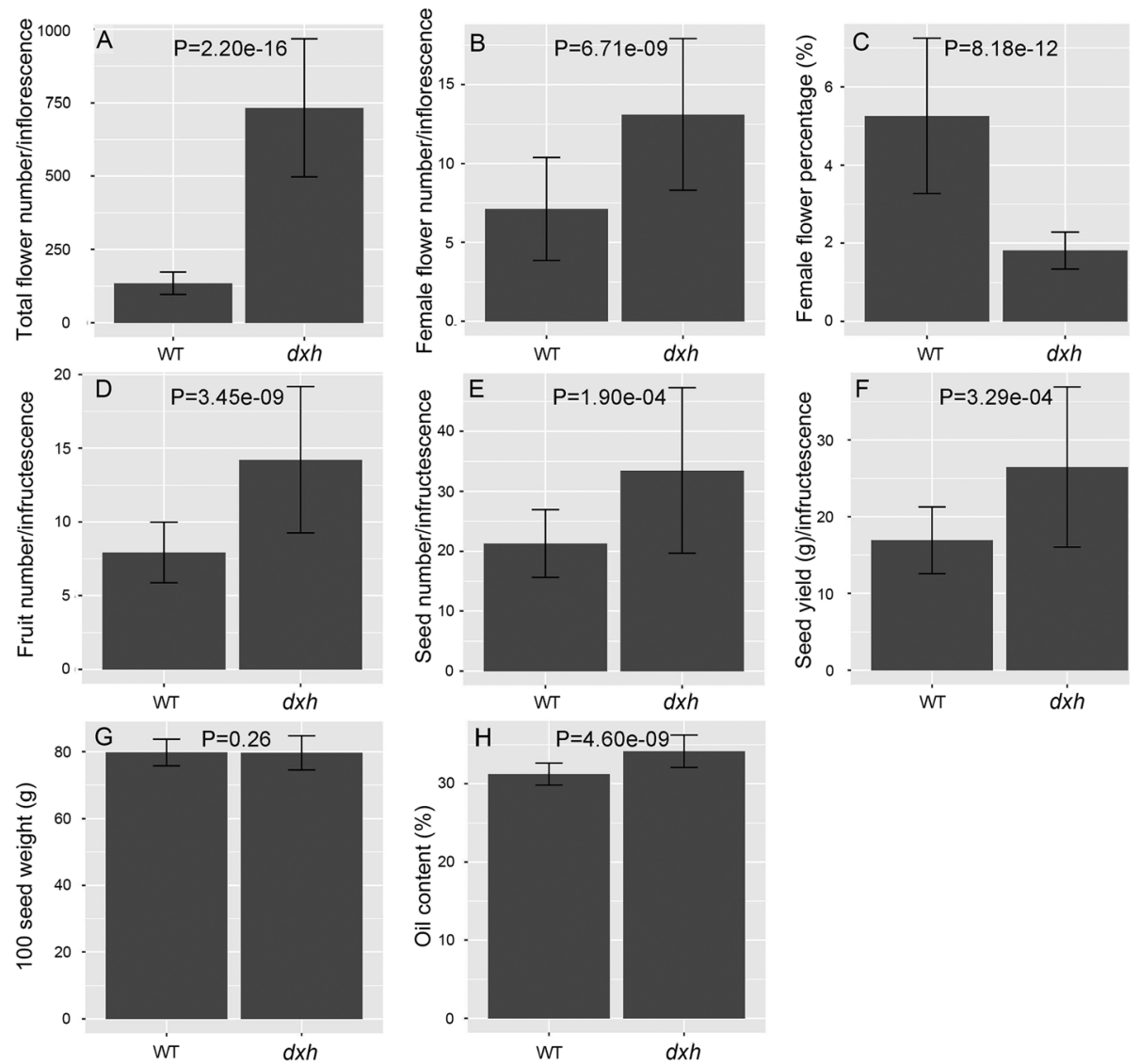

Fig. 2 Comparison of agronomic traits between WT plants and $d x h$ mutants. a Total flower number per inflorescence. b Female flower number per inflorescence. c Percentage of female flowers. $\mathbf{d}$ Fruit number per infructescence. e Seed number per infructescence. $\mathbf{f}$ Seed yield per infructescence. $\mathbf{g}$ 100-seed weight. $\mathbf{h}$ Seed oil content. The number of inflorescences/infructescences surveyed is 34-44; values are means \pm SD for (a-h). Statistical test analysis was performed using the Welch two sample t-test in R software

WT (gII_ckII) while 26 genes were downregulated in pairwise gII_ckII, and upregulated in dxhII_ckII (Fig. 3). Interestingly, ten of them were long noncoding RNAs (LncRNAs) [52], suggesting that LncRNA may be involved in the regulation of inflorescence branching in Jatropha.

\section{Differentially expressed genes involved in inflorescence development}

According to Arabidopsis and rice genes involved in inflorescence development, we identified 21 homologous genes that may play similar roles in regulating Jatropha inflorescence development from our assembled data set. Nine of them were differentially expressed in inflorescences in pairwise low-branch vs. high-branch mutant (gII_dxhII) (Fold change $\geq 2.0$ and FDR $<0.05$ ) (Additional file 7 ). Most of them exhibited opposite expression patterns between pairwise high-branch mutant vs. WT (dxhII_ckII) and low-branch mutant vs. WT (gII_ckII) (Fig. 4), which are coincided with their respective phenotypes. Expression of
Jatropha AGAMOUS-LIKE 6 (JcAGL6), FRUITFUL (JcFUL), JcLFY, SEPALLATA 1 (JcSEP1), JcSEP2a, JcSEP2b, JCSEP3 and WUSCHEL-RELATED HOMEOBOX 3 (JcWOX3) was upregulated, whereas expression of JCAGL24 and JCTFL1 was downregulated in pairwise lowbranch vs. high-branch mutant (gII_dxhII). In Arabidopsis, TFL1 promotes inflorescence branching, whereas $L F Y$ and $A P 1$ prevent inflorescence branching by repressing the expression of TFL1 in the floral meristem [7, 8, 10]. Our results showed that JcTFL1, JCLFY and JCAP1 may play similar roles in controlling inflorescence architecture in Jatropha, suggesting the function of these genes may be conservative in Jatropha and Arabidopsis.

\section{Differentially expressed genes involved in auxin and cytokinin metabolic and signaling pathways}

Auxin and cytokinin play important roles in inflorescence branching in Arabidopsis and rice [27, 28]. We identified 22 and 26 homologous genes involved in the auxin and cytokinin metabolic and signaling pathways, 


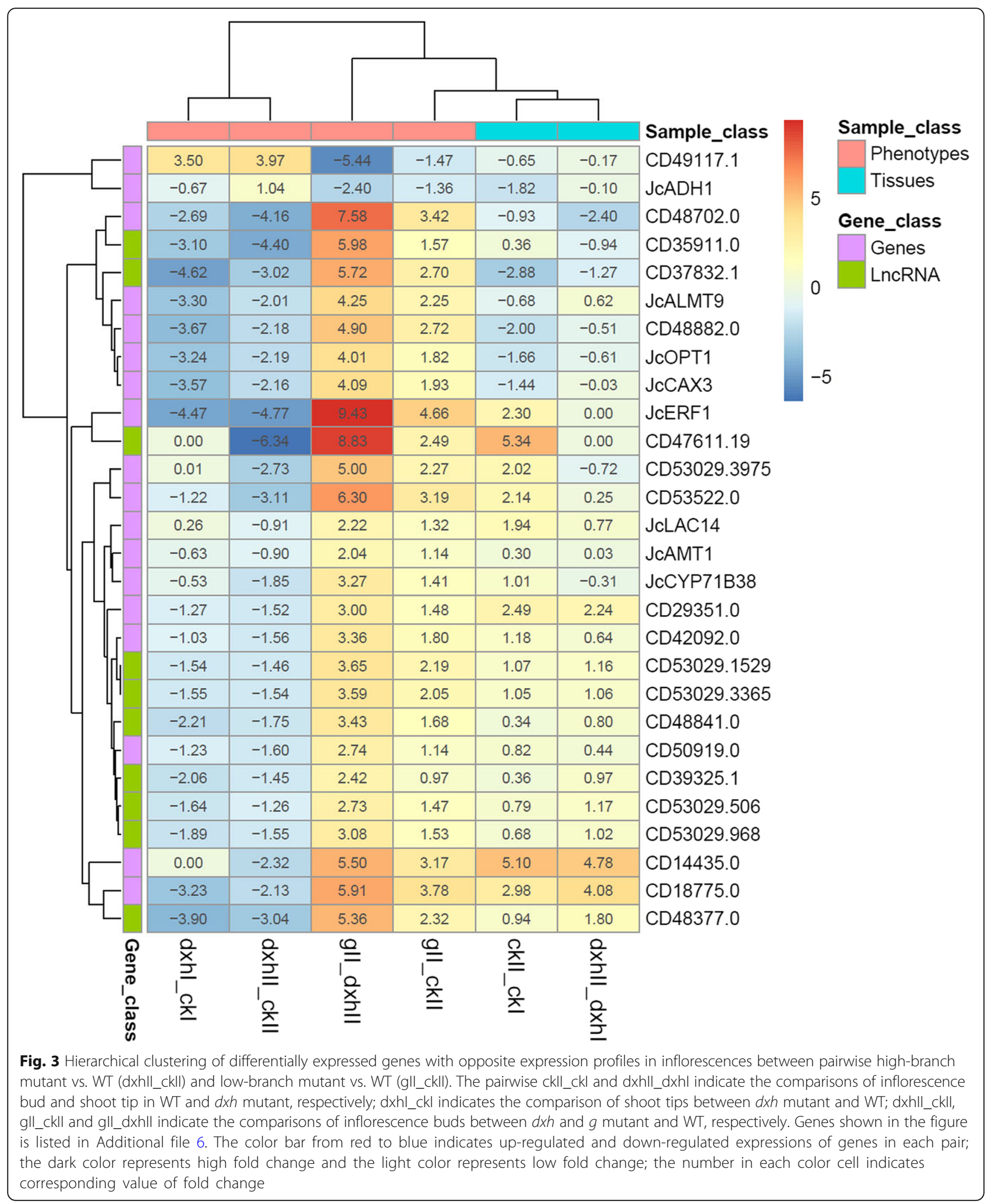

respectively, from our transcriptome data set (Additional file 8). Among them, Jatropha ALDEHYDE OXIDASE 1 (JCAAO1), CHALCONE SYNTHASE (JCCHS), cytochrome
P450, family 83, subfamily B, polypeptide 1 (JcCYP83B1), IAA carboxyl methyltransferase 1 (JCIAMT1), JCPID, JCPIN1, SMALL AUXIN UP RNA 20 (JCSAUR20), and 


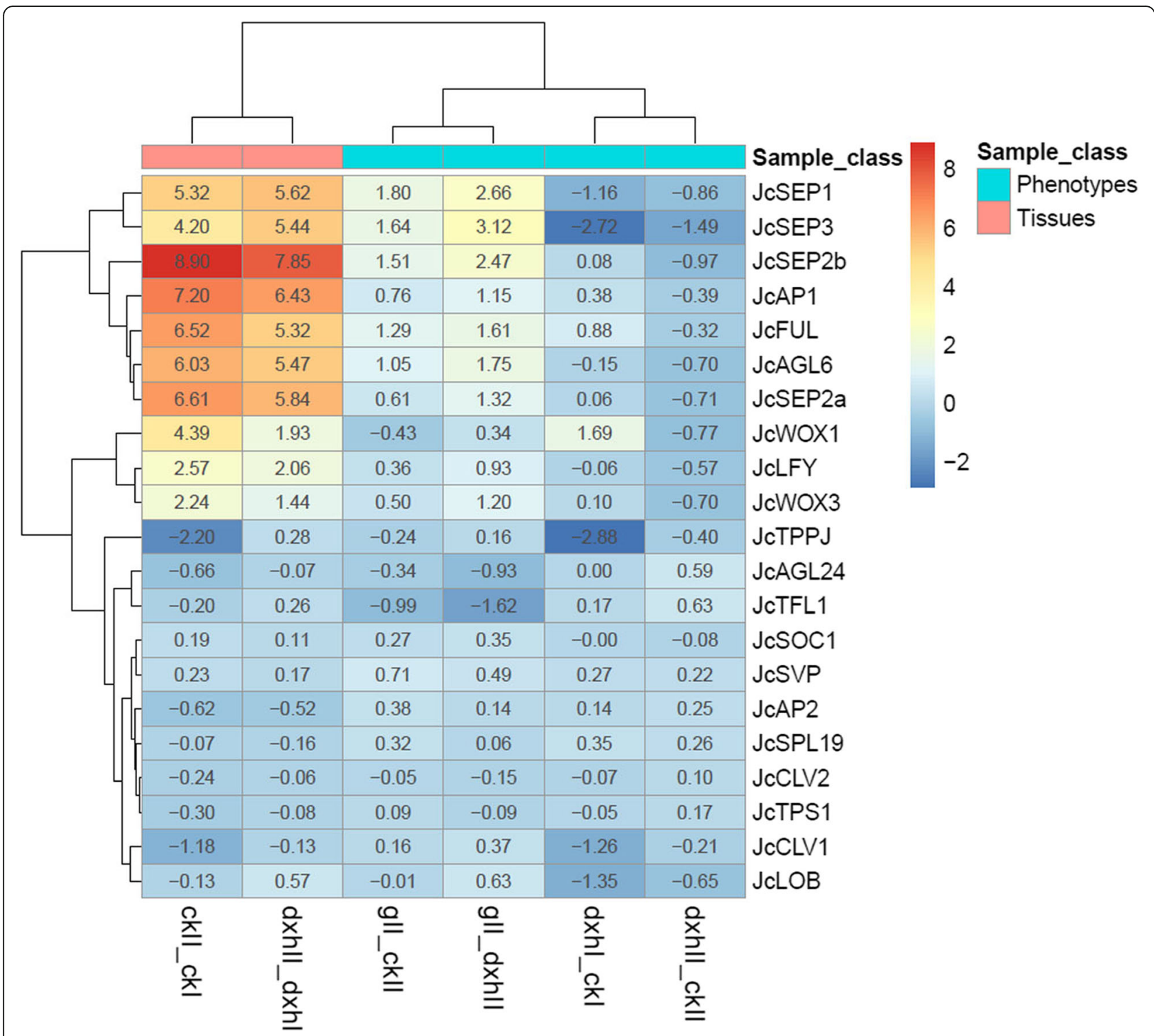

Fig. 4 Hierarchical clustering of differentially expressed genes involved in inflorescence development. The pairwise ckll_ckl, dxhll_dxhl, dxhl_ckl, dxhll_ckll, gll_ckll and gll_dxhll indicate the same pairs shown in Fig. 3. The genes shown in the figure is listed in Additional file 7. The color bar from red to blue indicates up-regulated and down-regulated expressions of genes in each pair; the dark color represents high fold change and light color represents low fold change; the number in each color cell indicates corresponding value of fold change

YUCCA4 (JcYUC4) may be involved in the auxin metabolic and signaling pathways. Jatropha CYTOKININ OXIDASE/DEHYDROGENASE 3 (JcCKX3), JCCKX7, ISOPENTENYLTRANSFERASE 1 (JCIPT1), JCIPT5, JCLOG1, JCLOG3, and JCLOG5 may be involved in the cytokinin metabolic and signaling pathways. All of them were differentially expressed in inflorescences in pairwise high-branch mutant vs. WT (dxhII_ckII) or low-branch mutant vs. WT (gII_ckII) (Fold change $\geq 2.0$ and FDR < 0.05) (Fig. 5). Thus, the auxin and cytokinin metabolic or signaling pathways may participate in regulating inflorescence branching in Jatropha.
Confirmation of expression profiles of candidate genes by real-time $\mathrm{qPCR}$

To validate the result of transcriptome analysis, we selected a dozen candidate genes to test their expression patterns across the five group samples using the realtime qPCR method. These genes included JCFUL, JCSEP1, JCSEP2A, JCSEP2B, JCSEP3, JCTFL1, JCCD35911.0, JcCD37832.1, JcCD39325.1, JcCD47611.19, JcCD53029.968 and $J_{c C D} 53029.1529$ (Additional files 9 and 10). Correlation analysis showed that the expression patterns of these genes displayed by RNA-Seq were consistent with that by real-time qPCR (Additional file 11), 


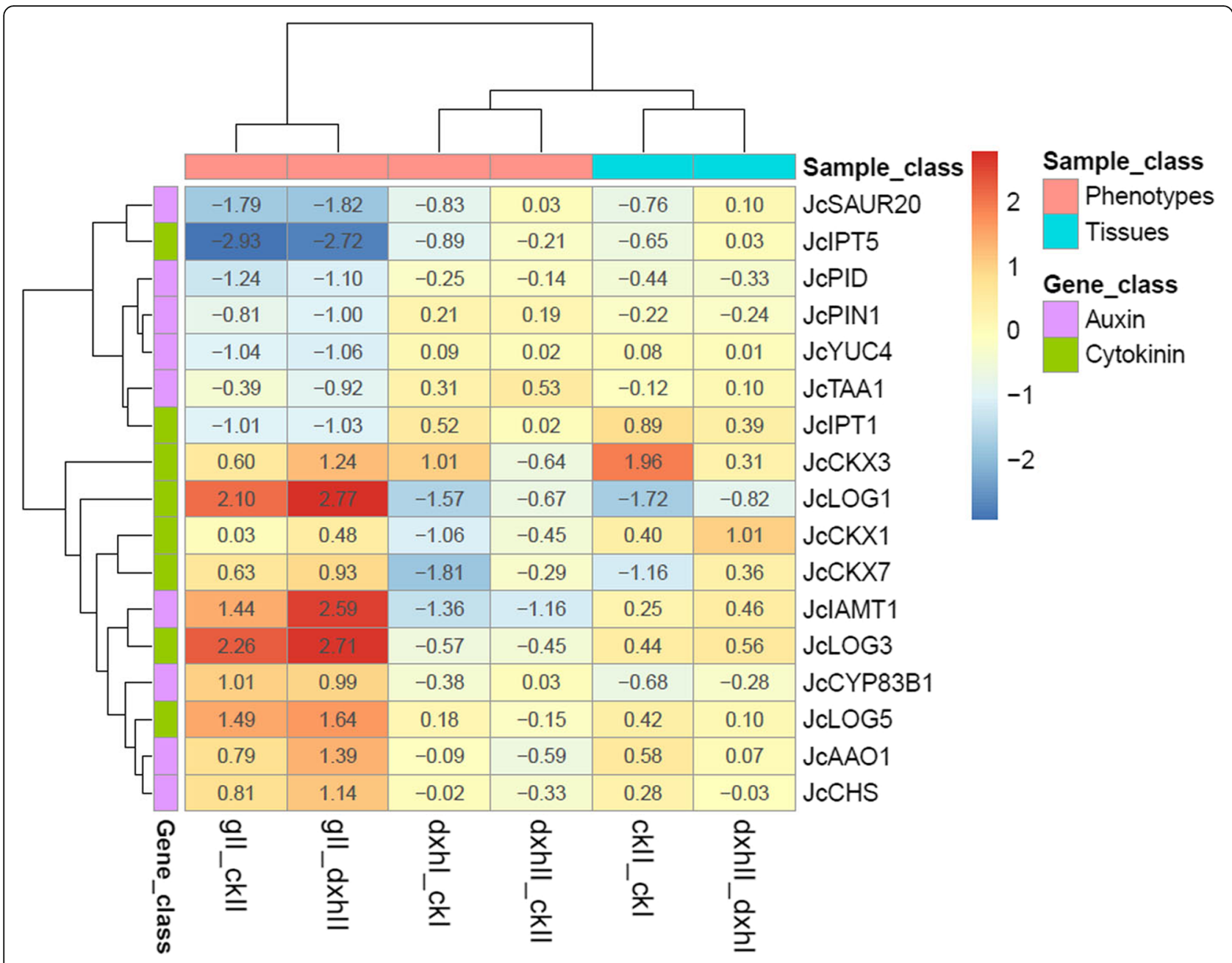

Fig. 5 Hierarchical clustering of differentially expressed genes involved in auxin and cytokinin metabolic or signaling pathways. The pairwise ckll_ckl, dxhll_dxhl, dxhl_ckl, dxhll_ckll, gll_ckll and gll_dxhll indicate the same pairs shown in Fig. 3. The genes shown in the figure is listed in Additional file 8. The color bar from red to blue indicates up-regulated and down-regulated expressions of genes in every pair; the dark color represents high fold change and light color represents fold change; the number in each color cell indicates corresponding value of fold change

indicating that the transcriptome results in this study are reliable.

\section{Construction of gene co-expression networks and identification of hub genes that regulate inflorescence branching}

We constructed a gene co-expression network using the WGCNA package [53]. In the network, 22 merged "modules" were identified; high correlation coefficients between genes in these modules indicated a high degree of interconnection (Additional file 12). The expression profile of each module was represented by its eigengene. We investigated the relationship between the module eigengenes and phenotype (three different inflorescence branching phenotypes) and tissue traits (shoot tips and inflorescence buds). MEblue and MEblack modules were highly associated with phenotype traits, and MEsalmon and MEdarkgreen modules were highly associated with deferent tissue traits (Fig. 6 and Additional file 13). We focused on the MEblue and MEblack modules because they might play more important roles in regulating inflorescence branching. According to the node connectivity that reflects how frequently a node interacts with others in a biological network and the results of transcriptome analysis, a dozen hub genes were identified from MEblue and MEblack modules (Figs. 7, 8 and Additional file 14). These genes include six Arabidopsis homologous genes, Jatropha ADENOSINE KINASE 2 (JcADK2), JCAPT1, JcCKX3, ISOPENTENYLTRANSFERASE 5 (JCIPT5), LONELY GUY 3 (JCLOG3) and JCLOG5 involved in the cytokinin metabolic pathway, four genes JCAAO1, JCPID, JCPIN1, and JCPIN3 in the auxin biosynthetic and signaling pathways, JCSOC1, SPATULA $(J c S P T)$ and five LncRNA genes. Among them, JcADK2, JcAPT1, JcCKX3, JcIPT5, JcLOG3, JcLOG5, JcPID, JcPIN1 and $J_{C P I N 3}$ were differentially expressed across different 


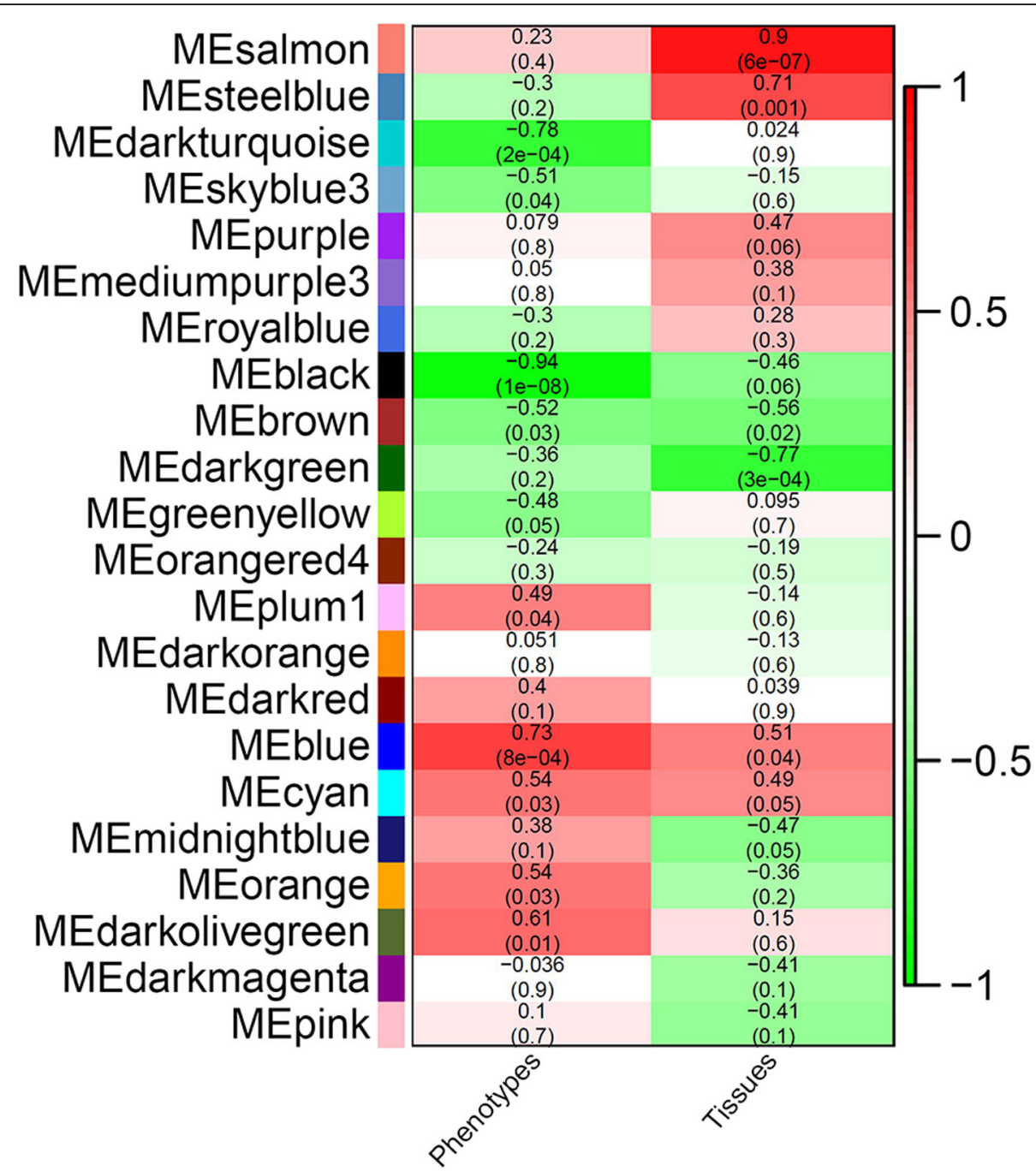

Fig. 6 Correlation analysis between module eigengenes (ME) and biological traits (phenotypes and tissues) using weighted gene correlation network analysis (WGCNA). Each color block in left color column indicates a module identified (22 modules). The right color bar indicates the correlation coefficient; the red color represents the positive correlation and green represents the negative correlation. Two middle columns correspond to phenotype and tissues traits; the numbers in each color cell indicate the correlation coefficient and the corresponding $P$-value (numbers in brackets) between modules and two traits, calculated using the WGCNA package

phenotypic inflorescences. The results showed that cytokinin and auxin metabolic or signaling pathways may participate in inflorescence development and may play vital roles in controlling inflorescence architecture.

\section{Application of 6-benzylaminopurine (6-BA) promoted an increase in inflorescence branches in both $g$ mutant and WT plants}

To validate the functions of cytokinin and auxin in inflorescence branching, we applied 6-BA (cytokinin) and 1naphthaleneacetic acid (NAA, auxin) to the inflorescence buds of low-branch mutant $(g)$ and WT plants, respectively. After 6-BA treatment, more than $70 \%$ of inflorescences displayed high-branch phenotype in both $g$ mutant and WT plants, although the growth of some inflorescence buds was arrested (Additional file 15 A, E and C, G). A three-order branch inflorescence became a four-order branch inflorescence in $g$ mutant plants (Additional file $15 \mathrm{~B}, \mathrm{~F}$ and $\mathrm{A}, \mathrm{E}$ ); and a five-order branch inflorescence became a six-order branch inflorescence in WT plants (Additional file $15 \mathrm{D}, \mathrm{H}$ and $C, G$ ), which is similar to the high-branch inflorescence phenotype of $d x h$ mutant. We postulate that a strong cytokinin activity is present in $d x h$ mutant inflorescence buds than in WT ones, which results in the high-branch inflorescence phenotype while a weak cytokinin activity in $g$ mutant inflorescence buds leads to the low-branch inflorescence phenotype. However, NAA treatment had no effect on inflorescence branching (data not shown). These results indicate that cytokinin is an important regulator in regulating inflorescence branching in Jatropha. 


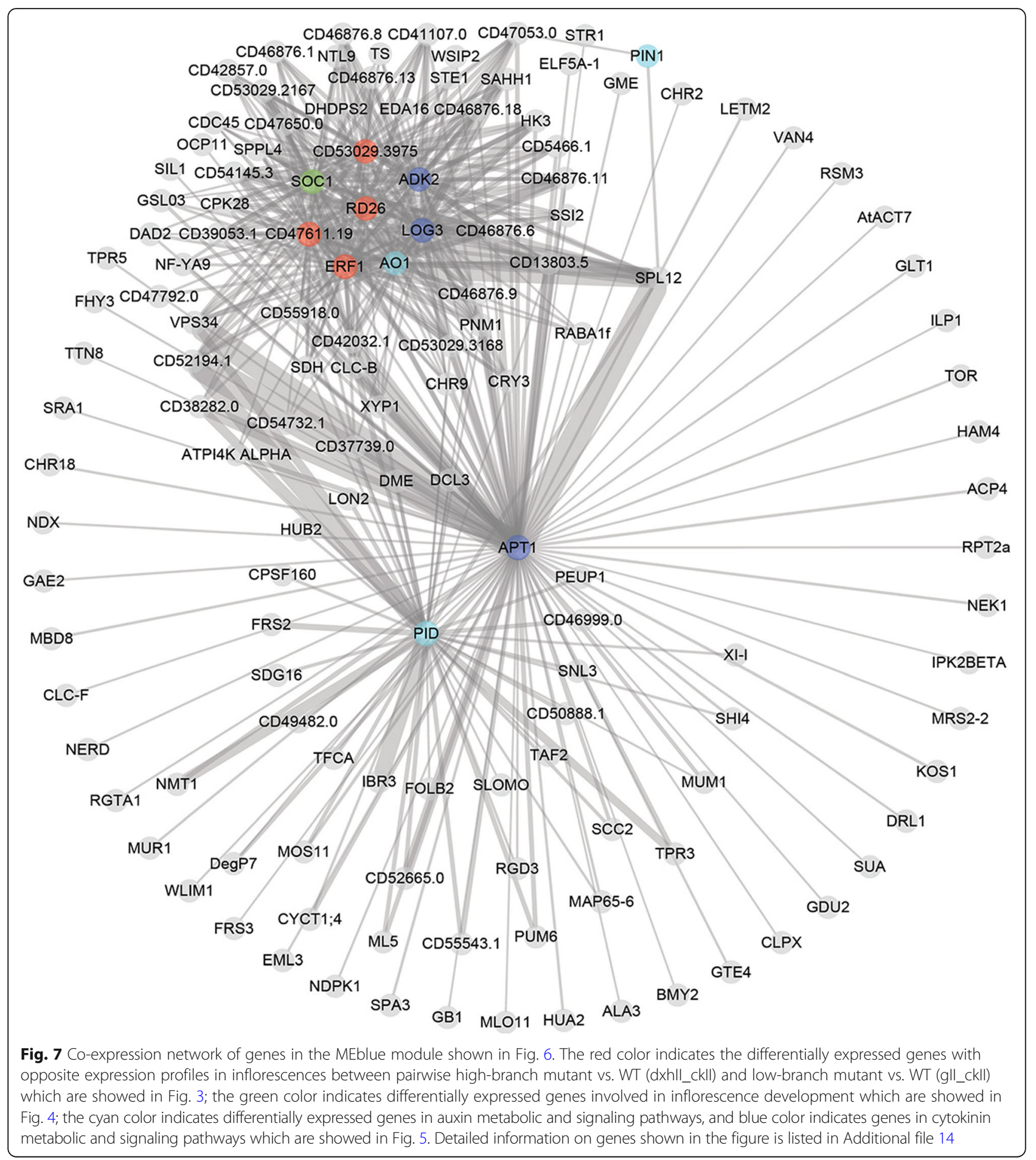

\section{Discussion}

In inflorescence development, cytokinin and auxin are essential for the formation and growth of the inflorescence branch meristem in Arabidopsis and rice [27, 28]. A gene co-expression network analysis showed that six homologous genes involved in the cytokinin metabolic pathway, and four genes in the auxin biosynthetic and signaling pathways are hub genes, which are from modules highly associated with inflorescence architecture phenotypes (Figs. 7 and 8), indicating that cytokinin and auxin likely to play important roles in regulating inflorescence branching in Jatropha. In cytokinin metabolic process, ADK catalyzes the phosphorylation of adenosine to AMP and converts cytokinin nucleosides to 


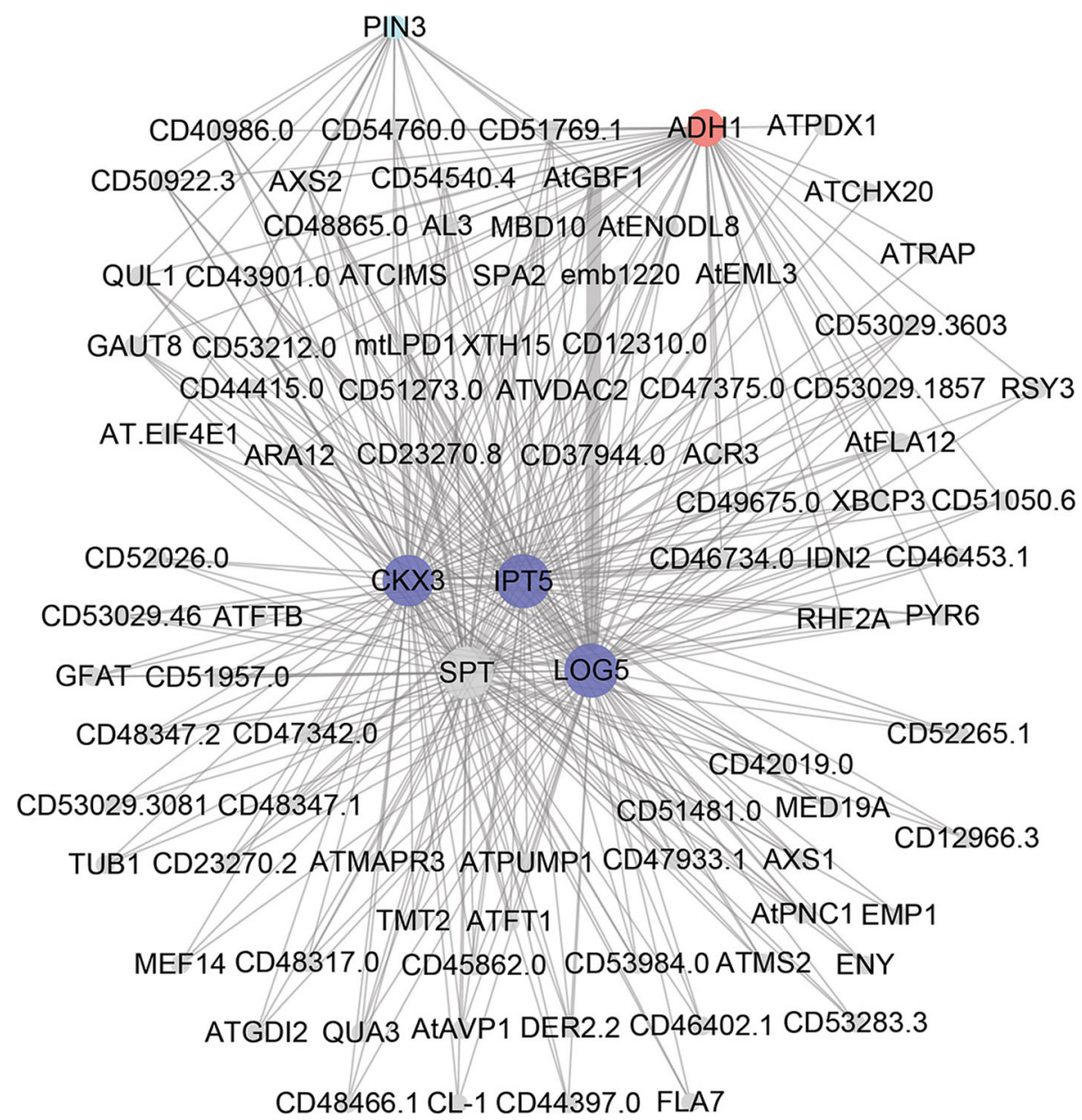

Fig. 8 Co-expression network of genes in the MEblack module shown in Fig. 6. The red color indicates the differentially expressed genes with opposite expression profiles in inflorescences between pairwise high-branch mutant vs. WT (dxhll_ckll) and low-branch mutant vs. WT (gll_ckll) which are showed in Fig. 3; the cyan color indicates the differentially expressed genes in auxin metabolic and signaling pathways, and the blue color indicates cytokinin metabolic and signaling pathways which are showed in Fig. 5. Detailed information on the genes shown in the figure is listed in Additional file 14

nucleotides contributing to intracellular CK homeostasis $[54,55]$. ATP1 converts active cytokinin to inactive form and loss of ATP1 activity causes high accumulation of cytokinin bases evoking abnormal cytokinin-regulated responses [56]. Isopentenyltransferases (IPTs) catalyze the formation of isopentenyladenosine 5 '-monophosphate (iPMP) from AMP and dimethylallylpyrophosphate (DMAPP), which is the first step of the cytokinin biosynthetic pathways [57]. LOG promotes cytokinin activity, and $\log$ mutants display a deficient in the maintenance of the shoot meristem in rice [28]. Cytokinin oxidases/dehydrogenases (CKXs) catalyze the irreversible degradation of cytokinins in cytokinin metabolic pathways [58]. In pairwise low-branch vs. high-branch mutant (gII_dxhII) and low-branch mutant vs. WT (gII ckII) inflorescences, the expression of JcIPT1 and JcIPT5 was downregulated while the expression of JcLOG1, $J_{c L O G 3}, J_{c L O G 5}, J_{c} C K X 1, J_{c} C K X 3$, and $J_{c} C K X 7$ was upregulated (Fig. 5). These results indicated that cytokinin biosynthesis is decreased, but cytokinin activation and degradation are promoted in low-branch mutant $(g)$ inflorescence compared to those in high-branch mutant $(d x h)$ and WT inflorescences. These effects may cause the low-branch inflorescence phenotype of $g$ mutant.

In Arabidopsis, TRYPTOPHANAMINOTRANSFERASE OF ARABIDOPSIS 1 (TAA1) catalyzes the conversion from L-tryptophan (Trp) to indole-3-pyruvic acid (IPA), and YUC FMOs catalyze the oxidative decarboxylation of IPA to generate indole-3-acetic acid (IAA), both of which are the key enzymes in auxin biosynthesis $[59,60]$. The expression of JcTAA1 and JcYUC4 was downregulated, indicating that auxin biosynthesis is decreased in low-branch $(g)$ mutant inflorescence compared to that in high-branch $(d x h)$ mutant inflorescence, along with the downregulated expression of JcPIN1 and $J_{C P I D}$ whose homologous genes serve as efflux carriers 
in auxin polar transport in Arabidopsis [61, 62] (Fig. 5). In addition, the expression of JCSAUR2O, an auxin responsive gene, was downregulated, and JCIAMT1 and $J c C H S$ were upregulated, confirming that auxin biosynthesis may be decreased in low-branch mutant $(g)$ inflorescence. In Arabidopsis, IAMT1 encodes an IAA carboxyl methyltransferase that converts IAA to methyl-IAA ester (MeIAA); the overexpression of MeIAA causes dramatic hyponastic leaf phenotypes [63]. CHS encodes the first enzyme in flavonoid biosynthesis that is considered an auxin transport inhibitor [64]. However, there is no reasonable explanation for the upregulated expression of $J_{C A A O 1}$ and $J_{C} C Y P 83 B 1$ genes, which are also involved in the auxin biosynthetic signaling pathways [65].

The application of 6-BA to inflorescence buds resulted in increased inflorescence branches both in low-branch mutant $(g)$ and WT plants (Additional file 15). In our previous research, 6-BA treatment on WT inflorescence buds significantly promoted total flower number per inflorescence meaning a high-branch inflorescence phenotype, which is positive correlation to 6-BA concentration [49]. Thidiazuron (TDZ), another synthetic compound with cytokinin activity, was also shown to promote initial inflorescence branching in WT plants, although the final branch number will be decreased because of the abortion of flower buds [66]. These results supported that cytokinin is an important regulator in controlling inflorescence branching, which is in agreement with our results of WGCNA analysis. Mutation of several genes involved in the cytokinin metabolic or signaling pathways causes abnormal inflorescence branching phenotypes in Arabidopsis and rice [37-39], suggesting that cytokinin might has a conserved role in regulating inflorescence branching in different species.

\section{Conclusions}

Using WGCNA, we identified several hub genes involved in the cytokinin metabolic pathway from modules highly associated with inflorescence architecture phenotypes. The application of cytokinin (6-BA) to inflorescence buds induced high-branch inflorescences both in low-branch mutant $(g)$ and WT plants. These results supported that cytokinin is an important regulator and may play vital role in controlling inflorescence branching in Jatropha. Several Arabidopsis homologous genes involved in inflorescence development is significantly differentially expressed in inflorescence buds between mutants and WT plants, indicating that they participate in the regulation of inflorescence architecture in Jatropha. Based on the above results, we speculate that the change of inflorescence branching phenotype of two mutants may result from mutations at one or more loci in genome regions that contain genes involved in cytokinin metabolism and/or in inflorescence development. Our results will be helpful for elucidating the regulatory mechanism of inflorescence architecture in Jatropha.

\section{Methods \\ Plant growth conditions and cytokinin (6-benzyladenine, 6-BA) treatment on inflorescence buds}

The wild-type (WT), duo xiao hua (dxh) and gynoecy $(g)$ mutant were grown in field in the Xishuangbanna Tropical Botanical Garden (XTBG) of the Chinese Academy of Sciences $\left(21^{\circ} \mathrm{N}, 101^{\circ} \mathrm{E}\right)$ located in Mengla County, Yunnan Province, China. WT plant has a four-order branch inflorescence under normal growth conditions, occasionally a three- or five-order branch inflorescence. The $d x h$ mutant has a high-branch inflorescence phenotype, a seven-order branch inflorescence, which was derived from a mutagenized population treated with cobalt-60 gamma rays. Its selfing progeny was selected until the stable high-branch inflorescence phenotype. The $g$ mutant has a low-branch inflorescence phenotype, a three-order branch inflorescence, which was derived from a natural variation [51]. The cutting-propagated plants from single plant with stable phenotype were used for the preparation of experimental materials. Two-yearold cutting-propagated plants were grown in a field at $2 \times 2 \mathrm{~m}$ per plant at the XTBG.

To confirm the effect of cytokinin on inflorescence branching, middle stage inflorescence buds (about 0.8 $\mathrm{cm}$ in diameter) that growth approximately 7-10 days from occurrence of invisible inflorescence bud of lowbranch mutant $(g)$ and WT plants were selected for once treatment with $1.0 \mathrm{mM}$ 6-BA solution containing $0.05 \%$ Tween-20. The 6-BA and mock solutions were sprayed onto inflorescence buds wetting them to the point of run-off, ten inflorescence buds from three to five plants per treatment. After 2-3 weeks, inflorescence phenotypes were surveyed. Seed oil content was measured by using the minispec mq-one Seed Analyzer (Bruker Optik $\mathrm{GmbH}$, Germany) as described previously [43], three replicates for each sample.

\section{Statistics of traits of high-branch inflorescence mutant (dxh) and WT}

During the suitable period, the total flower number, female flower number, ratio of female-to-male flowers, fruit number, seed number, seed yield, weight of 100 seeds, and seed oil content per inflorescence/infructescence were surveyed in high-branch inflorescence mutant $(d x h)$ and WT, respectively. In total 33 inflorescence/infructescence are surveyed in $d x h$ and 44 ones in WT. Statistical test analysis was performed using the Welch two sample t-test in R software (https://cran.rproject.org). 


\section{Collection of samples, RNA isolation and library construction}

At initial reproductive period, after removed leaves, shoot tips that can generate inflorescence meristem were harvested from $d x h$ and WT plants. Inflorescence buds that growth approximately 3-4 days from occurrence of invisible inflorescence bud (about $0.4 \mathrm{~cm}$ in diameter) were harvested from $d x h$ and $g$ mutants and WT plants. Three shoot tips or inflorescence buds were pooled as one biological replicate for RNA isolation, three replicates per sample. Total RNA extraction, library construction and quality control were performed as previously described [51]. Sequencing was performed on an Illumina Hiseq 2500 platform by Novogene Bioinformatics Technology (Beijing, China).

\section{De novo transcriptome assembly and read mapping}

Raw reads were treated with the Fastq_clean [67] and assessed with FASTQC (http://www.bioinformatics.babraham.ac.uk/projects/fastqc). De novo transcriptome assembly was performed using Trinity (version 2.0.6) with default parameters $[68,69]$. In all 122,526 sequences were generated. Bowtie version 1.1.1 ( $-\mathrm{v} 2-\mathrm{m} 10)$ was used for the mapping of the paired-end reads from each library [70].

\section{Identification of differentially expressed transcripts}

The Corset (version 1.03) was used for abundance estimation of transcripts [71]. Differentially expressed transcripts (DEGs) with a false discovery rate (FDR) of $<0.05$ were identified by using the edgeR package [72]. The Venny (version 2.1) was used for the generation of venn diagram of DEGs (http://bioinfogp.cnb.csic.es/tools/ venny/index.html). Hierarchical clustering of transcripts was performed using the pheatmap $\mathrm{R}$ package (version 1.0.7) (https://github.com/cran/pheatmap).

\section{Annotation of transcripts}

A total of 16,206 filtered transcripts used for differentially expressed analysis were annotated with BLASTX search against the Ensembl Plants database (http:// plants.ensembl.org) with Evalue $<1.0 \mathrm{E}-05$. Among them, 14,680 transcripts were annotated and 1526 were not found (Additional file 16). Ten transcripts displayed in Fig. 3 were defined as LncRNAs because they have not annotation, not coding protein and length $>200$ bp [52].

\section{Validation of expression profiles of candidate genes by real-time PCR (qPCR)}

RNA samples for qPCR are same as RNA-seq ones. The cDNA was synthesized from total RNA $(1.0 \mu \mathrm{g})$ using a PrimeScript RT Reagent Kit (Takara, Otsu, Japan), for each sample. qPCR was performed on a LightCycler 480 II (Roche, Penzberg, Germany) using the SYBR green I Kit (Roche), with three independent biological replicates for each sample and three technical replicates. JcGAPDH was as the internal reference. Primers for qPCR were listed in Additional file 10. The relative expression levels of genes were calculated by the $2^{-\Delta \Delta} \mathrm{CT}$ method. Correlation analysis between RNA-Seq and qPCR expression data of the genes is performed with cor.test in $\mathrm{R}$ software (https://cran.r-project.org).

\section{Construction and analysis of weighted gene co- expression networks}

The raw count data of differentially expressed genes, which were transformed with $\log _{2}(x+1)$, from edgeR were applied to construct co-expression networks using the $\mathrm{R}$ package weighted gene correlation network analysis (WGCNA) [53]. The soft thresholding power of 6 was chosen based on the criterion of approximate scalefree topology. The minimum module size was 30 , and modules were merged with the cutoff value of 0.2 . The interaction network was visualized using the Cytoscape software [73].

\section{Supplementary information}

Supplementary information accompanies this paper at https://doi.org/10 1186/s12870-019-2069-3.

Additional file 1. Sequencing read counts, quality, and alignment statistics for 15 Jatropha samples.

Additional file 2. Relationships of 15 inflorescence bud samples based on multidimensional scaling (MDS) analysis. The MDS plot is generated using plotMDS function in edgeR package. The distances between samples correspond to biological coefficient of variation (BCV) between those samples. ckl indicates the shoot tips of WT, containing ckl_1, ckl_2 and ckl_3 samples; ckll indicates the inflorescence buds of WT, containing ckll_1, ckll_2 and ckll_3 samples; dxhl indicates the shoot tips of $d x h$ mutant, containing $d x h l \_1, d x h l \_2$ and dxhl_3 samples; dxhll indicates the inflorescence buds of $d x h$ mutant, containing $d x h l l \_1$, dxhll_2 and dxhll_3 samples; and gll indicates the inflorescence buds of $g$ mutant, containing gll_1, gll_2 and gll_3 samples, respectively,

Additional file 3. Differentially expressed genes in inflorescences between six pairs in Jatropha. The pairwise ckll_ckl, dxhll_dxhl, dxhl_ckl, dxhll_ckll, gll_ckll and gll_dxhll indicate the same pairs shown in Fig. 3; blue lines indicate genes with a two-fold change; red points indicate genes with significantly different expression at a false discovery rate (FDR) of < 0.05. FC, fold change; CPM, counts per million mapped reads.

Additional file 4. List of differentially expressed genes identified in inflorescences between six pairs in Jatropha. The pairwise ckll_ckl, dxhll_dxhl, dxhl_ckl, dxhll_ckll, gll_ckll and gll_dxhll indicate the same pairs shown in Fig. 3.

Additional file 5. The overlap of differentially expressed genes in inflorescences between six pairs in Jatropha. The pairwise ckll_ckl, dxhll_dxhl, dxhl_ckl, dxhll_ckll, gll_ckll and gll_dxhll indicate the same pairs shown in Fig. 3. All differentially expressed transcripts in Additional file 5 were listed in Additional file 4.

Additional file 6. Differentially expressed genes with opposite expression patterns in inflorescences between pairwise dxhll_ckll and gll_dxhll.

Additional file 7. Homologous genes involved in inflorescence development in Jatropha.

Additional file 8. Homologous genes involved in the auxin and cytokinin metabolic and signaling pathways in Jatropha. 
Additional file 9. Validation of the expression profiles of 12 candidate genes by real-time qPCR. ckl and dxhl indicate the shoot tips of WT plants and $d x h$ mutants; ckll, dxhll and gll indicate inflorescence buds of $W T, d x h$ and $g$ mutants, respectively. JCGAPDH was as the internal reference. The error bars represent SD $(n=3)$.

Additional file 10. List of primers for $\mathrm{QPCR}$ validation.

Additional file 11. Correlation analysis between RNA-Seq and GPCR expression data of the genes shown in Additional file 9. The correlation analysis is performed with cor.test in R software. FC, fold change.

Additional file 12. Weighted co-expression network and modules identified by WGCNA analysis. Each leaf in the hierarchical cluster tree represents one gene; each row and column of the heat map plot corresponds to one gene; in the heat map, light color indicate weak coexpression, and dark color indicates strong co-expression; twenty-two modules were labeled by different colors.

Additional file 13. Correlation analysis of modules and phenotype traits. Each row and column represent one module; the red color represents high adjacency (positive correlation), and blue color represents low adjacency (negative correlation); red squares along the diagonal indicate the modules with similar expression patterns.

Additional file 14. Gene list in MEblack and MEblue modules. Additional file 15. Application of 6-benzylaminopurine (6-BA) promotes inflorescence branching of $g$ mutants and WT plants. (A)-(D) show the complete inflorescence, and $(E)-(H)$ show the dissected inflorescence, respectively. (A) and (E) indicate an increased inflorescence branching treated with 6-BA and (B) and (F) display a normal inflorescence branching of $g$ mutants with mock. $(C)$ and $(G)$ indicate an increase inflorescence branching treated with 6-BA and $(\mathrm{D})$ and $(\mathrm{H})$ display a normal inflorescence branching of WT plants with mock. The numbers in $(E)-(H)$ represent different orders of inflorescence branching. $B a r=5.0 \mathrm{~cm}$.

Additional file 16. Annotation of transcripts.

Additional file 17. Transcripts sequences used for the differential expression analysis.

\section{Abbreviations}

6-BA: 6-Benzyladenine; AAO: Aldehyde oxidase; ADK: Adenosine kinase; AGL: Agamous-like; AMP: Activated protein kinase; AP1: Apetala1;

APT: Adenine phosphoribosyl transferase; ATP: Atairp2 target protein; BA1: Barren stalk1; BIF: Barren infloresccence; $\mathrm{CHS}$ : Chalcone synthase CKX: Cytokinin oxidase/dehydrogenase; CLV: Clavata; CPM: Counts per million mapped reads; CR: Cox-reid profile-adjusted likelihood; CYP: Cytochrome P450; DEG: Differentially expressed genes;

DMAPP: Dimethylallylpyrophosphate; DST: Drought and salt tolerance; DXH: Duo xiao hua; FC: Fold change; FDR: False discovery rate;

FEA2: Fasciated ear2; FMO: Flavin monooxygenase; FUL: Fruitful; G: Gynoecy; GLM: Generalized linear model; IAA: Indol-3-acetic acid; IAMT: IAA carboxylmethyltransferase; IDS: Indeterminate spikelet; IPA: Indole-3-pyruvic acid; iPMP: Isopentenyladenosine 5'-monophosphate;

IPT: Isopentenyltransferase; LFY: Leafy; LncRNA: Long noncoding RNA; LOG: Lonely guy; MDS: Multidimensional scaling; MelAA: Methyl-IAA ester; MIR56: Microrna156; NAA: 1-Naphthaleneacetic acid; PID: Pinoid; PIN: Pinformed; qPCR: Real-time quantitative PCR; QTL: Quantitative trait locus; RA: Ramosa; RCN: Rice terminal flower 1/centroradialis homologs; RNASeq: RNA-sequence; SAM: Shoot apical meristem; SAUR: Small auxin up RNA; SEP: Sepallata; SID: S ister of indeterminate spikelet; SOC1: Suppressor of overexpression of constans 1; SPI1: Sparse inflorescence1; SPL: Squamosa promoter binding protein-like; SPT: Spatula; SVP: Short vegetative phase; TAA: Tryptophanaminotransferase of Arabidopsis; TAW1: Tawawa1; TD1: Tassel dwarf1; TDZ: Thidiazuron; TFL1: Terminal flower1; TRP: Tryptophan; UB3: Unbranched3; WFP: Wealthy farmer's panicle; WGCNA: Weighted gene correlation network analysis; WOX: Wuschel-related homeobox; WT: Wildtype; WUS: Wuschel; YUC: Yucca; ZCN: Zea centroradialis

\section{Acknowledgments}

The authors gratefully acknowledge the Central Laboratory of the Xishuangbanna Tropical Botanical Garden for providing high-performance computing and other research facilities.

\section{Authors' contributions}

Z-FX and M-SC designed the experiments and wrote the manuscript. M-SC analyzed the data and drafted the manuscript. M-SC and G-JW mutated Jatropha to obtain the desired mutant. M-SC, M-LZ, H-YH, XB, B-ZP, QF, Y-BT, $\mathrm{MT}$ and JMH carried out experiments. All authors reviewed the final manuscript. All authors agree to be accountable for the content of the work.

\section{Funding}

This work was supported by funding from the National Natural Science Foundation of China (31670612, 31370595, 31300568, and 31500500), the Program of Chinese Academy of Sciences (kfj-brsn-2018-6-008), and the CAS 135 program (2017XTBG-T02). Funding bodies were not involved in the design of the study, data collection and analysis, or interpretation of the manuscript.

\section{Availability of data and materials}

RNA-Seq data from $d x h$ and WT samples were deposited in NCBI under the accession number SRP122257. RNA-Seq data from three $g$ samples were deposited under accession numbers SRR4473569, SRR4473570 and SRR4473575 [51]. Transcriptome sequences referred to the differential expression analysis of genes were listed in Additional file 17

\section{Ethics approval and consent to participate}

Not applicable

\section{Consent for publication}

Not applicable

\section{Competing interests}

The authors declare that they have no competing interests.

\section{Author details}

${ }^{1}$ CAS Key Laboratory of Tropical Plant Resources and Sustainable Use, Xishuangbanna Tropical Botanical Garden, The Innovative Academy of Seed Design, Chinese Academy of Sciences, Menglun, Mengla 666303, Yunnan, China. ${ }^{2}$ Center of Economic Botany, Core Botanical Gardens, Chinese Academy of Sciences, Menglun, Mengla 666303, Yunnan, China. ${ }^{3}$ College of Life Sciences, University of Chinese Academy of Sciences, Beijing 100049, China. ${ }^{4}$ Instituto Nacional de Investigaciones Forestales, Agrícolas y Pecuarias, Campo Experimental Huimanguillo, Huimanguillo, Tabasco, Mexico.

Received: 4 December 2018 Accepted: 9 October 2019

Published online: 04 November 2019

\section{References}

1. Wyatt R. Inflorescence architecture: how flower number, arrangement, and phenology affect pollination and fruit-set. Am J Bot. 1982;69(4):585-94.

2. Prenner G, Vergara-Silva F, Rudall PJ. The key role of morphology in modelling inflorescence architecture. Trends Plant Sci. 2009;14(6):302-9.

3. Endress PK. Disentangling confusions in inflorescence morphology: patterns and diversity of reproductive shoot ramification in angiosperms. J Syst Evol. 2010;48(4):225-39.

4. Ma Q, Zhang W, Xiang Q-Y. Evolution and developmental genetics of floral display-a review of progress. J Syst Evol. 2017;55(6):487-515.

5. Brand U, Fletcher JC, Hobe M, Meyerowitz EM, Simon R. Dependence of stem cell fate in Arabidopsis on a feedback loop regulated by CLV3 activity. Science. 2000;289(5479):617-9.

6. Laux T, Mayer KF, Berger J, Jurgens G. The WUSCHEL gene is required for shoot and floral meristem integrity in Arabidopsis. Development. 1996; 122(1):87-96.

7. Schoof H, Lenhard M, Haecker A, Mayer KF, Jurgens G, Laux T. The stem cell population of Arabidopsis shoot meristems in maintained by a regulatory loop between the CLAVATA and WUSCHEL genes. Cell. 2000;100(6):635-44.

8. Bommert P, Lunde C, Nardmann J, Vollbrecht E, Running M, Jackson D, Hake S, Werr W. thick tassel dwarf1 encodes a putative maize ortholog of the Arabidopsis CLAVATA1 leucine-rich repeat receptor-like kinase. Development. 2005;132(6):1235-45.

9. Taguchi-Shiobara F, Yuan Z, Hake S, Jackson D. The fasciated ear2 gene encodes a leucine-rich repeat receptor-like protein that regulates shoot meristem proliferation in maize. Genes Dev. 2001;15(20):2755-66. 
10. Thompson BE, Hake S. Translational biology: from Arabidopsis flowers to grass inflorescence architecture. Plant Physiol. 2009;149(1):38-45.

11. Ratcliffe OJ, Bradley DJ, Coen ES. Separation of shoot and floral identity in Arabidopsis. Development. 1999;126(6):1109-20.

12. Shannon S, Meeks-Wagner DR. A mutation in the Arabidopsis TFL1 gene affects inflorescence meristem development. Plant Cell. 1991;3(9):877-92.

13. Ratcliffe OJ, Amaya I, Vincent CA, Rothstein S, Carpenter R, Coen ES, Bradley DJ. A common mechanism controls the life cycle and architecture of plants. Development. 1998;125(9):1609-15

14. Liljegren SJ, Gustafson-Brown C, Pinyopich A, Ditta GS, Yanofsky MF. Interactions among APETALA1, LEAFY, and TERMINAL FLOWER1 specify meristem fate. Plant Cell. 1999;11(6):1007-18.

15. Liu C, Teo ZW, Bi Y, Song S, Xi W, Yang X, Yin Z, Yu H. A conserved genetic pathway determines inflorescence architecture in Arabidopsis and rice. Dev Cell. 2013;24(6):612-22.

16. Nakagawa M, Shimamoto K, Kyozuka J. Overexpression of RCN1 and RCN2, rice TERMINAL FLOWER 1/CENTRORADIALIS homologs, confers delay of phase transition and altered panicle morphology in rice. Plant J. 2002;29(6): 743-50.

17. Danilevskaya ON, Meng X, Ananiev EV. Concerted modification of flowering time and inflorescence architecture by ectopic expression of TFL1-like genes in maize. Plant Physiol. 2010;153(1):238-51.

18. Yoshida A, Sasao M, Yasuno N, Takagi K, Daimon Y, Chen R, Yamazaki R, Tokunaga H, Kitaguchi Y, Sato Y, Nagamura Y, Ushijima T, Kumamaru T, lida S, Maekawa M, Kyozuka J. TAWAWA1, a regulator of rice inflorescence architecture, functions through the suppression of meristem phase transition. Proc Natl Acad Sci. 2013;110(2):767-72.

19. Jiao Y, Wang Y, Xue D, Wang J, Yan M, Liu G, Dong G, Zeng D, Lu Z, Zhu X, Qian Q, Li J. Regulation of OsSPL14 by OsmiR156 defines ideal plant architecture in rice. Nat Genet. 2010;42(6):541-4

20. Miura K, Ikeda M, Matsubara A, Song XJ, Ito M, Asano K, Matsuoka M, Kitano $\mathrm{H}$, Ashikari M. OsSPL14 promotes panicle branching and higher grain productivity in rice. Nat Genet. 2010;42(6):545-9.

21. Wang $L$, Zhang Q. Boosting rice yield by fine-tuning SPL gene expression. Trends Plant Sci. 2017;22(8):643-6.

22. Du Y, Liu L, Li M, Fang S, Shen $\mathrm{X}$, Chu J, Zhang Z. UNBRANCHED3 regulates branching by modulating cytokinin biosynthesis and signaling in maize and rice. New Phytol. 2017;214(2):721-33.

23. Chuck G, Meeley R, Hake S. Floral meristem initiation and meristem cell fate are regulated by the maize AP2 genes ids1 and sid1. Development. 2008; 135(18):3013-9.

24. Vollbrecht E, Springer PS, Goh L, Buckler Iv ES, Martienssen R. Architecture of floral branch systems in maize and related grasses. Nature. 2005;436(7054): 1119-26.

25. Satoh-Nagasawa N, Nagasawa N, Malcomber S, Sakai H, Jackson D. A trehalose metabolic enzyme controls inflorescence architecture in maize Nature. 2006:441(7090):227-30.

26. Bortiri E, Chuck G, Vollbrecht E, Rocheford T, Martienssen R, Hake S. ramosa2 encodes a LATERAL ORGAN BOUNDARY domain protein that determines the fate of stem cells in branch meristems of maize. Plant Cell. 2006;18(3): 574-85.

27. Barazesh S, McSteen P. Hormonal control of grass inflorescence development. Trends Plant Sci. 2008;13(12):656-62.

28. Kyozuka J. Control of shoot and root meristem function by cytokinin. Curr Opin Plant Biol. 2007:10(5):442-6.

29. Zhao Y, Christensen SK, Fankhauser C, Cashman JR, Cohen JD, Weigel D, Chory J. A role for flavin monooxygenase-like enzymes in auxin biosynthesis. Science. 2001;291(5502):306-9.

30. Gallavotti A, Barazesh S, Malcomber ST, Hall D, Schmidt RJ, McSteen P. sparse inflorescence 1 encodes a monocot-specific YUCCA-like gene required for vegetative and reproductive development in maize. Proc Natl Acad Sci. 2008;105(39):15196-201.

31. Okada K, Ueda J, Komaki MK, Shimura Y. Requirement of the auxin polar transport system in early stages of Arabidopsis floral bud formation. Plant Cell. 1991;3(7):677-84.

32. Bennett S, Alvarez J, Bossinger G. Morphogenesis in pinoid mutants of Arabidopsis thaliana. Plant J. 1995;8:505-20.

33. Hake S. Barren inflorescence 2 regulates axillary meristem development in the maize inflorescence. Development. 2001;128(15):2881-91.

34. Barazesh S. barren inflorescence 1 functions in organogenesis during vegetative and inflorescence development in maize. Genetics. 2008;179(1):389.
35. Ritter MK, Padilla CM, Schmidt RJ. The maize mutant barren stalk1 is defective in axillary meristem development. Am J Bot. 2002;89(2):203-10.

36. Huang $P$, Jiang H, Zhu C, Barry K, Jenkins J, Sandor L, Schmutz J, Box MS, Kellogg EA, Brutnell TP. Sparse panicle1 is required for inflorescence development in Setaria viridis and maize. Nature Plants. 2017;3:17054

37. Kurakawa T, Ueda N, Maekawa M, Kobayashi K, Kojima M, Nagato Y, Sakakibara H, Kyozuka J. Direct control of shoot meristem activity by a cytokinin-activating enzyme. Nature. 2007;445(7128):652-5.

38. Bartrina I, Otto E, Strnad M, Werner T, Schmulling T. Cytokinin regulates the activity of reproductive meristems, flower organ size, ovule formation, and thus seed yield in Arabidopsis thaliana. Plant Cell. 2011;23(1):69-80.

39. Ashikari M, Sakakibara H, Lin S, Yamamoto T, Takashi T, Nishimura A, Angeles ER, Qian Q, Kitano H, Matsuoka M. Cytokinin oxidase regulates rice grain production. Science. 2005;309(5735):741-5.

40. Li S, Zhao B, Yuan D, Duan M, Qian Q, Tang L, Wang B, Liu X, Zhang J, Wang J. Rice zinc finger protein DST enhances grain production through controlling Gn1a/OsCKX2 expression. Proc Natl Acad Sci. 2013;110(8):3167-72.

41. Sato S, Hirakawa H, Isobe S, Fukai E, Watanabe A, Kato M, Kawashima K Minami C, Muraki A, Nakazaki N, Takahashi C, Nakayama S, Kishida Y, Kohara M, Yamada M, Tsuruoka H, Sasamoto S, Tabata S, Aizu T, Toyoda A, Shin-i T, Minakuchi Y, Kohara Y, Fujiyama A, Tsuchimoto S, Kajiyama S, Makigano E, Ohmido N, Shibagaki N, Cartagena JA, et al. Sequence analysis of the genome of an oil-bearing tree, Jatropha curcas L. DNA Res. 2011;18(1):65-76.

42. Fairless D. Biofuel: the little shrub that could--maybe. Nature. 2007; 449(7163):652-5.

43. Pan B-Z, Xu Z-F. Benzyladenine treatment significantly increases the seed yield of the biofuel plant Jatropha curcas. J Plant Growth Regul. 2011;30(2):166-74.

44. Li C, Fu Q, Niu L, Luo L, Chen J, Xu Z-F. Three TFL1 homologues regulate floral initiation in the biofuel plant Jatropha curcas. Sci Rep. 2017:7:43090.

45. Li C, Luo L, Fu Q, Niu L, Xu Z-F. Identification and characterization of the FT/ TFL1 gene family in the biofuel plant Jatropha curcas. Plant Mol Biol Report. 2015;33(2):326-33

46. Tang MY, Tao YB, XU ZF. Ectopic expression of Jatropha curcas APETALA (JCAP1) caused early flowering in Arabidopsis, but not in Jatropha. PeerJ. 2016:4:e1969.

47. Ghosh A, Chikara J, Chaudhary DR, Prakash AR, Boricha G, Zala A. Paclobutrazol arrests vegetative growth and unveils unexpressed yield potential of Jatropha curcas. J Plant Growth Regul. 2010;29(3):307-15.

48. Song J, Chen M-S, Li J, Niu L, Xu Z. Effects of soil-applied paclobutrazol on the vegetative and reproductive growth of biofuel plant Jatropha curcas. Plant Diver Resour. 2013;35(2):173-9.

49. Chen M-S, Pan B-Z, Wang G-J, Ni J, Niu L, Xu Z-F. Analysis of the transcriptional responses in inflorescence buds of Jatropha curcas exposed to cytokinin treatment. BMC Plant Biol. 2014;14(1):318.

50. Pan B-Z, Chen M-S, Ni J, Xu Z-F. Transcriptome of the inflorescence meristems of the biofuel plant Jatropha curcas treated with cytokinin. BMC Genomics. 2014;15(1):974.

51. Chen M-S, Pan B-Z, Fu Q, Tao Y-B, Martínez-Herrera J, Niu L, Ni J, Dong Y, Zhao M-L, Xu Z-F. Comparative transcriptome analysis between gynoecious and monoecious plants identifies regulatory networks controlling sex determination in Jatropha curcas. Front Plant Sci. 2017;7:1953.

52. Chekanova JA. Long non-coding RNAs and their functions in plants. Curr Opin Plant Biol. 2015;27:207-16.

53. Langfelder $P$, Horvath S. WGCNA: an R package for weighted correlation network analysis. BMC Bioinformatics. 2008;9(1):559.

54. Moffatt BA, Wang L, Allen MS, Stevens YY, Qin W, Snider J, von Schwartzenberg K. Adenosine kinase of Arabidopsis. Kinetic properties and gene expression. Plant Physiol. 2000;124(4):1775-85.

55. Schoor S, Farrow S, Blaschke H, Lee S, Perry G, von Schwartzenberg K, Emery N, Moffatt B. Adenosine kinase contributes to cytokinin interconversion in Arabidopsis. Plant Physiol. 2011;157(2):659-72.

56. Zhang $X$, Chen Y, Lin X, Hong X, Zhu Y, Li W, He W, An F, Guo H. Adenine Phosphoribosyl Transferase 1 is a key enzyme catalyzing Cytokinin conversion from Nucleobases to nucleotides in Arabidopsis. Mol Plant. 2013;6(5):1661-72.

57. Kakimoto T. Identification of plant cytokinin biosynthetic enzymes as dimethylallyl diphosphate: ATP/ADP isopentenyltransferases. Plant Cell Physiol. 2001:42(7):677-85.

58. Schmülling T, Werner T, Riefler M, Krupková E, Bartrina y Manns I. Structure and function of cytokinin oxidase/dehydrogenase genes of maize, rice, Arabidopsis and other species. J Plant Res. 2003;116(3):241-52. 
59. Stepanova AN, Robertson-Hoyt J, Yun J, Benavente LM, Xie DY, Dolezal K, Schlereth A, Jurgens G, Alonso JM. TAA1-mediated auxin biosynthesis is essential for hormone crosstalk and plant development. Cell. 2008;133(1): 177-91.

60. Mashiguchi K, Tanaka K, Sakai T, Sugawara S, Kawaide H, Natsume M, Hanada A, Yaeno T, Shirasu K, Yao H, McSteen P, Zhao Y, Hayashi K, Kamiya $\mathrm{Y}$, Kasahara H. The main auxin biosynthesis pathway in Arabidopsis. Proc Natl Acad Sci. 2011;108(45):18512-7.

61. Blilou I, Xu J, Wildwater M, Willemsen V, Paponov I, Friml J, Heidstra R, Aida M, Palme K, Scheres B. The PIN auxin efflux facilitator network controls growth and patterning in Arabidopsis roots. Nature. 2005;433(7021):39-44.

62. Christensen SK, Dagenais N, Chory J, Weigel D. Regulation of auxin response by the protein kinase PINOID. Cell. 2000;100(4):469-78.

63. Qin G, Gu H, Zhao Y, Ma Z, Shi G, Yang Y, Pichersky E, Chen H, Liu M, Chen Z. An indole-3-acetic acid carboxyl methyltransferase regulates Arabidopsis leaf development. Plant Cell. 2005;17(10):2693-704.

64. Brown DE, Rashotte AM, Murphy AS, Normanly J, Taque BW, Peer WA, Taiz L, Muday GK. Flavonoids act as negative regulators of auxin transport in vivo in Arabidopsis. Plant Physiol. 2001;126(2):524-35.

65. Seo M, Akaba S, Oritani T, Delarue M, Bellini C, Caboche M, Koshiba T. Higher activity of an aldehyde oxidase in the auxin-overproducing superroot1 mutant of Arabidopsis thaliana. Plant Physiol. 1998;116(2): 687-93.

66. Pan B-Z, Luo Y, Song L, Chen M-S, Li J-L, Xu Z-F. Thidiazuron increases fruit number in the biofuel plant Jatropha curcas by promoting pistil development. Ind Crop Prod. 2016:81:202-1.

67. Zhang M, Zhan F, Sun H, Gong X, Fei Z, Gao S: Fastq_clean: an optimized pipeline to clean the Illumina sequencing data with quality control. In: Proceedings of the IEEE International Conference on Bioinformatics and Biomedicine (IEEE BIBM 2014). Belfast, UK: 2014;44-48.

68. Grabherr MG, Haas BJ, Yassour M, Levin JZ, Thompson DA, Amit I, Adiconis X, Fan L, Raychowdhury R, Zeng Q, Chen Z, Mauceli E, Hacohen N, Gnirke A, Rhind N, di Palma F, Birren BW, Nusbaum C, Lindblad-Toh K, Friedman N, Regev A. Full-length transcriptome assembly from RNA-Seq data without a reference genome. Nat Biotechnol. 2011;29(7):644-52.

69. Haas BJ, Papanicolaou A, Yassour M, Grabherr M, Blood PD, Bowden J, Couger MB, Eccles D, Li B, Lieber M, MacManes MD, Ott M, Orvis J, Pochet N, Strozzi F, Weeks N, Westerman R, William T, Dewey CN, Henschel R, LeDuc RD, Friedman N, Regev A. De novo transcript sequence reconstruction from RNA-seq using the trinity platform for reference generation and analysis. Nat Protoc. 2013;8(8):1494-512.

70. Langmead B, Trapnell C, Pop M, Salzberg SL. Ultrafast and memory-efficient alignment of short DNA sequences to the human genome. Genome Biol. 2009:10(3):R25

71. Davidson NM, Oshlack A. Corset: enabling differential gene expression analysis for de novo assembled transcriptomes. Genome Biol. 2014; 15(7):410

72. Robinson MD, McCarthy DJ, Smyth GK. edgeR: a bioconductor package for differential expression analysis of digital gene expression data. Bioinformatics. 2010;26(1):139-40,

73. Shannon P, Markiel A, Ozier O, Baliga NS, Wang JT, Ramage D, Amin N, Schwikowski B, Ideker T. Cytoscape: a software environment for integrated models of biomolecular interaction networks. Genome Res. 2003;13(11): 2498-504.

\section{Publisher's Note}

Springer Nature remains neutral with regard to jurisdictional claims in published maps and institutional affiliations.

Ready to submit your research? Choose BMC and benefit from:

- fast, convenient online submission

- thorough peer review by experienced researchers in your field

- rapid publication on acceptance

- support for research data, including large and complex data types

- gold Open Access which fosters wider collaboration and increased citations

- maximum visibility for your research: over $100 \mathrm{M}$ website views per year

At BMC, research is always in progress.

Learn more biomedcentral.com/submissions 